\title{
Morning glory disc anomaly
}

INSERM

\section{Source}

INSERM. (1999). Orphanet: an online rare disease and orphan drug data base. Morning glory disc anomaly. ORPHA:35737

A congenital optic disc anomaly characterized by a funnel shaped excavation of the posterior fundus that incorporates the optic disc. Clinically, the optic disc malformation resembles the morning glory flower. Morning glory disc anomaly (MGDA) is usually unilateral and often results in a decrease in best-corrected visual acuity (BCVA). MGDA can be isolated or associated with other ocular or non-ocular anomalies. 